\title{
Incidence of antibodies in women after failure of assisted reproduction
}

\author{
Bobak $\mathrm{L}^{1}$, Bobakova $\mathrm{D}^{2}$, Vaczy $\mathrm{Z}^{1}$, Rosocha $\mathrm{J}^{1}$, Halagovec $\mathrm{A}^{3}$ \\ Associated Tissue Bank, Medical Faculty, Safarik University and Luis Pasteur University Hospital, \\ Kosice, Slovakia. Daniela.Bobakova@upjs.sk
}

\begin{abstract}
Objectives: The aim of this study is to determine to what degree antisperm allo-antibodies (ASA), anti-ovarian antibodies (AOA), anti-zona pellucida antibodies (AZPA) and seven anti-phospholipid antibodies (APLA) can explain the failure of assisted reproduction technology (ART) in women.

Background: Among the causes of reproductive failure are allo- and autoimmune reactions of the organism against reproductive tissues and cells.

Methods: We examined a sample of 43 selected women aged 27 to 45 after failure of assisted reproduction technology (ART) via intrauterine insemination (IUI), in vitro fertilization (IVF) or intracytoplasmic sperm injection (ICSI). Sera from these women were tested by ELISA (enzyme-linked immunosorbent assay) (total Ig) for the presence of anti-sperm allo-antibodies (ASA), anti-ovarian antibodies (AOA), anti-zona pellucida antibodies (AZPA) and seven anti-phospholipid antibodies (APLA).

Results: We found $22(51 \%)$ patients positive for the examined antibodies. Among patients with positive results were 3 miscarriages, 3 biochemical pregnancies ( $\uparrow \mathrm{hCG}$ ) and 16 with no evidence of conception. Positive APLA was found in 17 patients. Selected immunological parameters were negative in 21 (49\%) patients, which means that the tested allo- and auto-antibodies did not cause the failure of ART.

Conclusion: This demonstrates that the range of diagnostic tests limits the success of diagnosis and the method of dealing with infertile couples. The use of cardiolipin as a screening test appears to be insufficient, because in our sample it would have caused a $35 \%$ error rate. Investigation of antibodies against seven phospholipids is thus considered to be reasonable and is beneficial for infertility diagnosis (Tab. 2, Ref. 36). Text in PDF www.elis.sk. Key words: autoimmunity, alloimmunity, anti-sperm antibodies, anti-ovarian antibodies, anti-zona pellucida antibodies, anti-phospholipid antibodies, assisted reproduction, infertility.
\end{abstract}

Allo- and autoimmunity in reproduction can be defined as a set of immune reactions directed against the reproductive tissues, reproductive cells or structures, or against other cells, tissues and structures involved indirectly in processes associated with fertility, fertilization and full-term birth of a healthy child.

\section{Anti-sperm antibodies (ASA): Allo-antibodies against sperm}

Several possible mechanisms have been suggested for the creation of antispermatic immunity in women. Isoimmunization may occur after phagocytosis of sperm by immunocompetent cells in the female reproductive tract (1) and subsequent presentation of spermatic antigens to the immune system. This mechanism is not yet entirely clear and is subject to further investigation (2). Other mechanisms are the cross-reactivity mechanism with microbial antigens and that of potentiating the immune response

${ }^{1}$ Associated Tissue Bank, Medical Faculty, Safarik University and Luis Pasteur University Hospital, Kosice, Slovakia, ${ }^{2}$ Institute of Public Health, Department of Health Psychology, Medical Faculty, Safarik University, Kosice, Slovakia, and ${ }^{3}$ Dermato-venerological clinic, Medical Faculty, Safarik University and Luis Pasteur University Hospital, Kosice, Slovakia

Adress for correspondence: D. Bobakova, MSc, Graduate School Kosice Institute for Society and Health, Institute of Public Health - Dept. of Health Psychology, Medical Faculty, Safarikiensis University, Trieda SNP 1, SK04001 Kosice, Slovakia. with interferon gamma (production of anti-idiotype antibodies) in women whose male partners have anti-sperm antibodies in the semen (3).

In the etiology of ASA, cervix uteri surgery (4); chronic traumatization of the cervix; inflammation; sexually transmitted infections (STI) (5) caused by pathogens such as Chlamydia trachomatis, Mycoplasma hominis, M. genitalium and Ureaplasma urealyticum; $(6,7)$ and some aerobic or anaerobic bacteria or protozoa (Trichomonas vaginalis) predominate. Viruses such as CMV, HSV I, II and HPV may also play a role in initiating ASA formation (8).

Treatment of ASA includes treatment of infections in combination with coitus condomatus and subsequent immunosuppressive therapy (prednisone and hydrocortisone) (9). Assisted reproduction is also indicated, the ICSI (Intra Cytoplasmic Sperm Injection) method in particular (10). If ASA is present in the cervical mucus, the use of intrauterinal insemination (IUI) is both appropriate and effective (11).

\section{Anti-ovarian antibodies (AOA): Auto-antibodies against ovarian tissues}

Anti-ovarian autoimmunity is comprised of a heterogeneous group of auto-antibodies against ovarian antigens. These include anti-oocyte plasma (ooplasma), oocyte membrane (zona pellucida), 
different parts of the ovary (membrane granulose, theca folliculi interna) and luthein - follicular cells $(12,13,14)$.

In the etiology of AOA formation, chronic inflammation of the ovaries, laparoscopic abdominal surgery (removal of adhesions after previous inflammation and removal of an inflamed appendix), the collection of oocytes for ART and autoimmune premature ovarian failure (POF) predominate.

In some cases, the causes of POF are unclear and are defined as idiopathic. Hoek et al (1997) found an association of POF with adrenal autoimmunity and/or Addison's disease. Other authors $(16,17)$ have found that systemic lupus erythematodus (SLE), antinuclear antibody (ANA) and rheumatoid factor occur more often in patients with POF than in reproductively healthy women. The relationship between POF and SLE, which in $84 \%$ of cases is complicated by the presence of AOA, is especially important (18). Systemic diseases such as primary Sjogren's syndrome, much like secondary antiphospholipid syndrome (APS), can be associated with AOA. Recently published articles document the presence of auto-antibodies against human heat-shock protein $90-\beta$ (anti-HSP90 $\beta$ ) in the sera of infertile women. This protein causes ovarian autoimmunity and is considered to be a marker of ovarian damage also associated with POF (19).

\section{Anti-zona pellucida antibodies (AZPA): Auto-antibodies against the zona pellucida}

These types of antibodies occur most often after two or more in vitro fertilizations (IVF) and in women with endometriosis (20). Antibodies in the cervical mucus may occur as a result of local infection in the area of the reproductive organs. The presence of antibodies significantly correlates with infection by Ureaplasma urealyticum and Mycoplasma hominis (7). The presence of AZPA is considered to be one of the serious causes of infertility and of IVF failure.

AZPA may occur in blood serum, in secretions in the abdomen and in follicular fluid or cervical mucus (7). Treatments for infertility caused by AZPA are micromanipulation-assisted reproductive techniques (ART) such as ICSI or assisted hatching in combination with immunosuppressive therapy (20).

\section{Anti-phospholipid antibodies (APLA): Auto-antibodies against phospholipids}

Some of the interactions that occur both inside cells with regard to phospholipids are part of the blood coagulation cascade, and their failure is related to the presence of APLA. APLA cause pregnancy complications such as miscarriage, premature birth and fetal growth restriction, because unlike other tissues, the placenta is more vulnerable to the effects of APLA. The placenta expresses phospholipids on the surface of villi, which are involved in the transfer of nutrients and oxygen from maternal blood (21). This condition is called primary anti-phospholipid syndrome (pAPS). It is characterized by the presence of APLA, lupus anticoagulant and anti-B2 glycoprotein I (anti- $\beta 2$ GPI), but evidence on connective tissue disease is lacking $(22,23)$.
Antibodies and recurrent thrombosis are also present in secondary APS and may also be associated with pregnancy loss; moreover, they are associated with lymphoproliferative diseases, oncologic diseases and particularly autoimmune diseases of connective tissues, such as SLE and others (23). The most common consequences of APLA are miscarriage, ART failure and idiopathic infertility. Treatment of APS includes anticoagulation, immunosuppressive and antioxidant therapies (24). Combined therapies are also used in repeated IVF failures due to positive ANA, APS, lupus anticoagulant (LAC) and rheumatoid factor.

The aim of this study was to determine to what degree antisperm allo-antibodies (ASA), anti-ovarian antibodies (AOA), anti-zona pellucida antibodies (AZPA) and 7 anti-phospholipid antibodies (APLA) can explain the failure of assisted reproduction technology (ART) in women.

\section{Methods}

A sample of 43 women were examined at the Laboratory for Diagnostics of Infertility and sperm bank at the Associated Tissue Bank, Medical Faculty, Safarik University and Luis Pasteur's University Hospital in Kosice, Slovakia, due to failure of ART, IUI, IVF and ICSI. Patients were age 27 to 45 (mean 32.6, median 33, SD 3.66). Sera from these women were tested by ELISA (total Ig) for the presence of ASA, AOA and AZPA by commercial sets from BIOSERV Diagnostics, Germany. APLA (cardiolipin - CL, phosphatidylethanolamin - PEA, phosphatidylinosithol - PI, phosphatidyl acid - PA, phosphatidylglycerol - PG, phosphatidylserine - PS, and phosphatidylcholine - PCH were tested by ELISA assembled in our department. Antigens were obtained from SIGMA, USA.

\section{Results}

ART failure in the 43 patients sampled included 9 miscarriages, 7 biochemical pregnancies $(\uparrow \mathrm{hCG})$ and 27 cases without evidence of conception. There were $22(51 \%)$ patients (age range 28-38 years, mean 33.6, median 34, SD 2.94) positive for at least one of the tested parameters (Tab. 1), eighteen of whom were over 30 years old. In the 22 cases showing positive results, there were 3 miscarriages, 3 biochemical pregnancies $(\uparrow \mathrm{hCG}$ ) and 16 cases without evidence of conception (Tab. 1). For detailed information regarding the positive tests in these patients see Table 1.

A positive result for ASA was detected in 7 cases, for AOA in 10 cases, and for AZPA in 4 cases, (Tab. 1). A positive test for at least one of the APLA was detected in 17 cases (Tab. 2). The most frequent positive result obtained for APLA found in our sample (Tab. 2) was for the presence of PI (64.7\%). Out of the 10 samples negative for CL there were 6 samples positive for PI, 5 for PA, 5 for PG, 5 for PS and 5 positive for $\mathrm{PCH}$.

\section{Discussion}

The aim of this study is to determine to what degree ASA, AOA, AZPA and APLA can explain the failure of ART in women. We provided data on the incidence of antibodies against the re- 
Tab. 1. Incidence of individual antibodies in 22 positive patients.

\begin{tabular}{|c|c|c|c|c|c|c|c|c|c|c|c|c|c|}
\hline Patient & Age & ASA & $\mathrm{AOA}$ & AZPA & $\mathrm{CL}$ & PEA & PI & PA & PG & PS & $\mathrm{PCH}$ & ART & Results \\
\hline 1 & 30 & - & + & - & - & - & - & - & - & - & - & IUI 4, IVF 1 & 0 \\
\hline 2 & 34 & + & + & + & - & - & - & - & - & - & - & IVF 3 & 0 \\
\hline 3 & 28 & - & + & - & - & - & + & - & - & - & - & IVF 3 & 0 \\
\hline 4 & 33 & + & + & + & + & + & + & + & + & + & + & IUI 2, IVF 3 & $1 \mathrm{x} \uparrow \mathrm{hCG}$ \\
\hline 5 & 37 & - & + & - & - & - & - & - & - & - & - & IUI 1, IVF 2 & $2 \mathrm{xM}$ \\
\hline 6 & 34 & - & - & - & + & - & + & + & - & + & - & IVF 1 & 0 \\
\hline 7 & 36 & - & + & - & - & - & - & - & - & - & - & IVF 1 , ICSI 1 & 0 \\
\hline 9 & 35 & - & + & + & - & - & - & - & - & - & - & IUI 2 & 0 \\
\hline 10 & 34 & - & + & - & + & - & - & - & - & - & - & IVF 1 , ICSI 1 & $1 \mathrm{x} \uparrow \mathrm{hCG}$ \\
\hline 11 & 34 & - & - & - & + & - & + & + & - & + & - & IVF 1 & 0 \\
\hline 12 & 34 & - & - & - & + & + & + & + & + & - & - & IVF 1 & 0 \\
\hline 13 & 29 & - & - & - & + & - & + & - & - & - & - & IUI 2 & 0 \\
\hline 14 & 34 & - & - & - & + & + & - & + & - & + & - & IUI 4, IVF 1 & 0 \\
\hline 15 & 34 & - & - & - & - & + & - & - & + & - & + & IVF 1 & 0 \\
\hline 17 & 38 & + & + & - & - & + & + & + & - & + & + & IUI 2, IVF 2 & 0 \\
\hline 18 & 31 & + & - & + & - & + & + & + & + & - & + & IVF 2 & 0 \\
\hline 19 & 37 & + & - & - & - & - & - & + & + & + & + & ICSI 5 & $1 \times M$ \\
\hline 20 & 28 & + & - & - & - & - & - & - & + & + & - & ICSI 1 & 0 \\
\hline 21 & 36 & - & - & - & - & - & - & + & - & + & - & IVF 2 & $2 \times M$ \\
\hline 22 & 35 & + & - & - & - & + & + & - & - & - & + & IUI 3, IVF 2 & 0 \\
\hline Total & & 7 & 10 & 4 & 7 & 7 & 11 & 8 & 6 & 8 & 5 & & \\
\hline
\end{tabular}

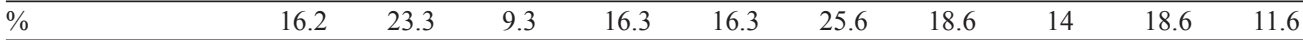

ASA - Anti - sperm antibodies; AOA - Anti - ovarian antibodies; AZPA - Anti - zona pellucida antibodies; CL - cardiolipin; PEA - hosphatidylethanolamin; PI phosphatidylinosithol; PG - phosphatidylglycerol; PS - phosphatidylserine; PCH - phosphatidylcholine; IUI - intrauterine insemination; IVF - in vitro fertilization; ICSI - intracytoplasmic sperm injection; $\uparrow$ hCG - biochemical pregnancy; M - miscarriage; 0 - without evidence of conception

Tab. 2. Anti-phospholipid antibodies present in 17 positive patients.

\begin{tabular}{ccccccccc}
\hline Patient & CL & PEA & PI & PA & PG & PS & PCH & Total + \\
\hline 1 & - & - & + & - & - & - & - & 1 \\
2 & + & + & + & + & + & + & + & 7 \\
3 & + & - & + & + & - & + & - & 4 \\
4 & - & - & + & + & + & + & - & 4 \\
5 & + & - & - & - & - & - & - & 1 \\
6 & + & - & + & + & - & + & - & 4 \\
7 & + & + & + & + & + & - & - & 5 \\
8 & + & - & + & - & - & - & - & 2 \\
9 & + & + & - & + & - & + & - & 4 \\
10 & - & + & - & - & + & - & + & 3 \\
11 & - & - & + & - & - & - & - & 1 \\
12 & - & + & + & + & - & + & + & 4 \\
13 & - & + & + & + & + & - & + & 5 \\
14 & - & - & - & + & + & + & + & 4 \\
15 & - & - & - & - & + & + & - & 2 \\
16 & - & - & - & + & - & + & - & 2 \\
17 & - & + & + & - & - & - & + & 3 \\
\hline Total & 7 & 7 & 11 & 9 & 7 & 9 & 6 & $17=39.5 \%$ \\
\hline
\end{tabular}

CL - cardiolipin; PEA - hosphatidylethanolamin; PI - phosphatidylinosithol; PG - phosphatidylglycerol; PS - phosphatidylserine; PCH - phosphatidylcholine

productive cells and tissues in a sample of 43 patients with ART failure. Our results confirm that the examined antibodies negatively affect the success of ART but do not fully explain the failure of ART, as we found $49 \%$ of patients negative for all of the examined parameters.

In our sample ASA was involved in 7 cases of IUI, IVF and ICSI failure, which represents $16.2 \%$ of the study sample $(n=43)$ and $31.8 \%$ of the women positive for at least one of the tested parameters $(n=22)$. Positive results for ASA occurred only in the combination with positive results for other antibodies. ASA was accompanied by positive results for AOA and/or AZPA in 2 cases. In 6 cases it was accompanied by a positive result for different phospholipids. Therefore, the share of the effect of ASA on ART failure is difficult to assess. The occurrence of ASA in our sample resulted in one miscarriage, 5 ART failures and one biochemical pregnancy ( $\uparrow \mathrm{hCG}$ ). Positive results for ASA in our sample could be the result of manipulation in the cervix uteri during ART and/ or undiagnosed latent urogenital infections.

ASA may disrupt the process of fertilization at different stages (25). The crucial factor is in which antigens ASA are directed against. ASA appears to operate through a wide variety of mechanisms. For example, antibodies against the fertilization antigen FA-1 and the peptide YLP12 are important because they block the binding of sperm on the oocyte (26), which might be one of the likely mechanisms of natural fertilization and IUI failure. The occurrence of ASA in fertile couples also suggests that not all ASA are able to impair fertility (10). It is likely that ASA is involved in the development of infertility particularly in combination with other antibodies (AOA, AZPA, APLA).

Ten women were found to be AOA positive, which represents $23.3 \%$ of study sample $(n=43)$ and $45.5 \%$ of the women positive for at least one of the tested parameters $(n=22)$. These were the states after the IVF and ICSI methods, which means that the presence of AOA could be due to oocyte aspiration. Gobert et al. (1992) also acknowledge this possibility, and increasing the number of IVF attempts may cause an increase in AOA as well. One patient in the study sample was pregnant 2 times after IVF. The pregnancies resulted in miscarriage, and aside from the AOA positive, no other positives were detected. In 4 cases AOA was 
detected together with AZPA. If a positive result for AZPA were to be part of the AOA positive, we could assume that AZPA are dominant in these 4 cases. Other types of AOA may be targeted against other ovarian structures such as granulosa, theca interna cells and corpus lutheum fibroblasts. In 3 cases, the presence of AOA was detected simultaneously with other antibodies. One patient was positive for all 10 examined antibodies. This patient underwent 2 IUI and 3 embryo transfers after IVF, resulting in one biochemical pregnancy ( $\uparrow$ hCG) and 4 cases without evidence of conception. In this patient, the positive result for ANA was also found independently from our study. This may indicate an initial phase of systemic disease and/or POF $(16,17)$.

Little is known about the exact origin of ovarian antigens recognized by serum antibodies. The manufacturer of the ELISA sets, Bioserv (Germany), describes them only as a mix of ovarian proteins. Identification and characterization of target antigens is a condition for clarifying the nature of immunological mechanisms and also for the creation of better approaches to the diagnosis and treatment of infertility due to ovarian failure (19). A high incidence of AOA is found in women with autoimmune POF who experienced ART failure. This could mean that AOA plays a crucial role in ART failure $(27,28)$.

The presence of AZPA is considered to be one of the most serious causes of infertility and IVF failure. AZPA occurred in 4 cases, which represents $9.2 \%$ of the study sample $(n=43)$ and $18.2 \%$ of the women positive for at least one of the tested parameters $(n=22)$. The history is dominated by $2-3$ cycles of IVF or IUI. AZPA did not occur separately, but only in combination with ASA, AOA and APLA. The causes of AZPA incidence are probably micromanipulation techniques used during ART and/or latent urogenital infections. AZPA mostly occur after two or more IVF procedures, and together with ASA, occur in women with endometriosis (29). In 3 of 4 cases of the study sample, the presence of AZPA was detected together with ASA. Zona pellucida plays the role of autoantigen $(13,7)$. It is presented as highly immunogenic and can also be a target antigen in ovarian autoimmunity $(30,31)$ and the cause of POF (32).

AZPA seem to occur significantly more often in infertile women compared with healthy women (33). It is assumed that AZPA block the sperm-oocyte interaction by preventing akrozoma reactions (20). In another study, the ELISA test detected positive IgG antibodies against recombinant human ZP3 in 3 of 34 patients with POF. But 3 of 6 postmenopausal women were also positive, thus it is likely that antibodies against ZP3 are the result of damage to ovarian follicles rather than its cause (15).

Many diagnostic laboratories use detection of antibodies against CL as a screening test, but in our sample, only 7 cases $(41.2$ $\%$ ) out of 17 were positive for CL. In 10 cases (58.8\%), CL was negative, but positive results for other phospholipids, particularly for PI, were found. This implies that if CL detection is used as a screening test, then $58.8 \%$ of positive cases fail to be revealed. Our findings are supported by those of Ulčová-Gallová et al. (2005), who confirmed that antibodies against PI and PA are of higher importance in regard to ART failure, and those of Bizzaro et al (2005), who also confirmed the detection of CL to be insufficient as a screening test and recommended the detection of antibodies against cofactors (plasma proteins binding phospholipids) such as ß2-glycoprotein 1, prothrombin and anexin V.

Infections in the small pelvis and genital tract can negatively affect the results of ART, particularly embryo nidation, and can also increase the number of spontaneous miscarriages (35). The effect of infections on the ART failure can be direct, by influencing endometrial receptivity (35), or indirect, by inducing the production of antibodies (4). IVF failure can be caused by adherent microorganisms which negatively influence the interaction of sperm with oocytes by masking sperm equatorial fibronectin (36).

Infertility as a civilization disease has a multi-factorial etiology and requires cooperation between several medical specializations. It has been confirmed that the range of laboratory tests limits the clarification of causes of fertility failure and failures with the management of infertile couples. Our study highlights this fact, in that $21(49 \%)$ patients had negative results in the examined parameters, meaning that the cause of ART failure was not clarified. It was confirmed that the investigated antibodies do significantly reduce the success of natural and assisted reproduction. STI are at the forefront of the etiology of production of antibodies against the reproductive cells and tissues. It is unknown whether the women from our sample have been examined or treated for STI before ART and to what extent STI contributed to their ART failure. But the possible negative effect of STI in our patients on ART is supported by studies which have found that the presence of pathogenic microflora in the genital tract of women and men lead to worse IVF outcomes $(8,10,20,35)$. Therefore, high quality microbiological tests are of great importance.

ART is often used as a primary solution for infertility before detailed diagnosis of its possible causes can be performed, leading to frequent ART failure. Moreover, as a result of incomplete diagnostics, systemic diseases or STI might be overlooked. Women from our sample belong to group of patients in whom ART was preferred prior to complex diagnostics, and these women were referred to our department only after ART failure. We consider such an approach as a failure of management of infertile couples. Even in our sample, the causes of ART failure were not fully clarified, thus we recommend further extending the range of laboratory tests.

\section{References}

1. Tomlinson MJ, White A, Barratt CL et al. The removal of morphologically abnormal sperm forms by phagocytes: a positive role for seminal leukocytes? Hum Reprod 992; 7: 517-522.

2. Cibulka J, Ulčová-Gallová Z, Balvín M, Bibková K, Mičanová Z. Izolace a imunologická identifikace spermaglutinační protilátky z lidského séra. Čes Gynek 2009; 74: 201-208.

3. Clarke GN. Etiology of sperm immunity in women. Fertil Steril 2009; 9: 639-643.

4. Mazumdar S, Levine AS. Antisperm antibodies: etiology, pathogenesis, diagnosis, and treatment. Fertil Steril 1998; 70: 799-808.

5. Robertson SA. Seminal plasma and male factor signalling in the female reproductive tract. Cell Tissue Res 2005; 322: 43-52. 
6. Ulčová-Gallová Z, Hort T. Immunoreactivity of Mycoplasma hominis PG21 antigens and human sperm antigens. Čes Gynek 1992; 57: 418-421.

7. Al-Daghistani HI, Fram KM. Incidence of anti-zona pellucida and anti-sperm antibodies among ingfertile Jordanian women and its relation to mycoplasmas. Eastern Mediterranean Health J 2009; 15: 1263-1271.

8. Dostál J, Oborná I, Talaš M, Chrastinová L, Machovská K. Infekční agens a léčba infertility metodou IVF + ET. Čes Gynek 1996; 61: 144-147.

9. Ulčová-Gallová Z, Mráz L, Pláničková E et al. Imunomodulace hydrocortisonem u sterilních žen. 5. kongres Čes. imunolgů 5.-9.7.1988. Plzeň, Imunol. zpravodaj ČSAV, 1988; 1: 98.

10. Chamley LW, Clarke GN. Antisperm antibodies and conception. Semin Imunopathol 2007; 29: 169-184.

11. Agarval A. Treatment of immunological infertility by sperm washing and intrauterine insemination. Arch Androl 1992; 29: 207-213.

12. Forges T, Monnier-Barbarino P, Faure G, Bene M. Autoimmunity and antigenic targets in ovarian pathology. Hum ReprodUpdate 2004; 10: $163-175$.

13. Koyama K, Hasegawa A. Premature ovarian failure syndrome may be induced by autoimmune reactions to zona pellucida proteins. J Reproduktionsmed Endokrinol 2006; 3: 94-97.

14. Pires ES, Meherji PK, Vaidya RR, Parikh FR, Ghosalkar MN, Khole VV. Specific and sensitive immunoassay detects multiple anti-ovarian antibodies in women with infertility. J Histochem Cytochem 2007; 55: 1181-1190.

15. Hoek A, Schoemaker J, Drexhage HA. Premature Ovarian Failure and Ovarian Autoimmunity. Endocrine Reviews 1997; 18: 107-134.

16. Pekonen F, Siegberg R, Makinen T, Miettinen A, Yli-Korkala O. Immunological disturbances in patients with premature ovarian failure. Clin Endocrinol 1986; 25: 1-6.

17. Mignot MH, Schoemaker J, Kleingeld M, Rao BR, Drexhage HA. Premature ovarian failure. I. The association with autoimmunity. Eur J Obstet Gynecol Reprod Biol 1989; 30: 59-66.

18. Moncayo-Naveda H, Moncayo R, Benz R, Wolf A, Lauritzen C. Organ-specific antibodies against ovary in patients with systemic lupus erythematosus. Am J Obstet Gynecol 1989; 160: 1227-1229.

19. Pires ES, Khole VV. A block in the road to fertility: auto-antibodies to heat-sock protein $90-\beta$ in human ovarian autoimmunity. Ferti Steril 2009; 92: 1395-1409.

20. Ulčová-Gallová Z, Babčová Z, Nováková K, Mičanová P, Rokyta Z. Antizonální protilátky v ovulačním hlenu a v séru pacientek s poruchami reprodukce. Čes Gynek 2004; 69: 215-218.

21. McIntyre JA. Antiphospholipid antibodies (aPL) in implantation failures. Am J Reprod Immunol 2003; 49: 221-229.

22. Miyakis S, Locksin MD, Atsumi T et al. International consensus statement on an update of the classification criteria for definite antiphospholipid syndrome (APS). J Thromb Haemost 2006; 4: 295-306.
23. Shoenfeld Y, Meroni PL, Toubi E. Antiphospholipid syndrome and systemic lupus erythematosus: are they separate entities or just clinical presentations on the same scale? Curr Opin Rheumatol 2009; 21: 495-500.

24. Ulcova-Gallova Z, Krauz V, Novákova $P$ et al. Anti-phospholipid antibodies against phosphatidylinositol, and phosphatidylserine are more significant in reproductive failure than antibodies against cardiolipin only. Am J Reprod Immunol 2005; 54: 112-117.

25. Arefi S, Tehrani M J, Akhondi M M et al. Anti-zona pellucida antibodies in infertile patients in relation to multiple puncture of ovaries and unexplained infertility. Iran J Reprod Med 2005; 3: 30-35.

26. Williams J, Samuel A, Naz RK. Presence of antisperm antibodies reactive with peptide epitopes of FA-1 and YLP12 in sera of immunoinfertile women. Am J Reprod Immunol 2008; 59: 518-524.

27. Gobert B, Barbarino-Monnier P, Guillet-May F, Bene MC, Faure GC. Anti ovarian antibodies after attempts at human in vitro fertilization induced by follicular puncture rather than hormonal stimulation. J Reprod Fertil 1992; 96: 213-218.

28. Monnier-Barbarino P, Bene MC, Gobert B, Landes P, Guillet-Rosso F, Faure G. Antiovary antibodies, repeated attempts, and outcome of in vitro fertilization. Fertil Steril 1991; 56: 928-932.

29. Iborra A, Palacio JR, Ulčová-Gallová Z, Martinez P. Autoimmune response in women with endometriosis. Am J Reprod Immunol 2000; 44: $236-241$.

30. Kelkar R, Mherji P, Kadam S, Gupta S, Nandedkar T. Circulating auto-antibodies against the zona pellucida and thyroid microsomal antigen in women with premature ovarian failure. J Reprod Immunol 2005; 11: 53-67.

31. Koyama K, Hasegawa A, Mochida N, Calongos G. Follicular dysfunction induced by autoimmunity to zona pellucida. Reprod Biol 2005; 5: $269-278$.

32. Govind C, Srivastava N, Gupta S. Evaluation of the immunocontraceptive potential of Escherichia coli expressed recombinant non-human primate zona pellucida glycoproteins in homologous animal model. Vaccine 2002; 21: 78-88.

33. Kamada M, Daitoh T, Mori K et al. Etiological implication of autoantibodies to zona pellucida in human female infertility. Am J Reprod Immunol 1992; 28: 104-109.

34. Bizzaro N, Tonutti E, Villalta D, Tampoia M, Tozzoli R. Prevalence and clinical correlation of anti-phospholipid-binding protein antibodies in anticerdiolipin-negative patients with systemic Lupus erythematosus and women with unexplained recurrent miscarriages. Arch Pathol Lab Med 2005; 129: 61-68.

35. Paseková V, Veselá K, Tauwinklová G, Veselý J. Vliv mikrobního prostředí na procesy in vitro fertilizace. Čes Gynek 2001; 66: 435-440.

36. Glander HJ, Hermann K, Haustein UF. Impairment of the fertilization process by adherence of microorganism to the equatorial fibronectin band (EFB) of human sperm. A pathogenic hypothesis. Int Urol Nephrol 1990; 22: 483-486. 